
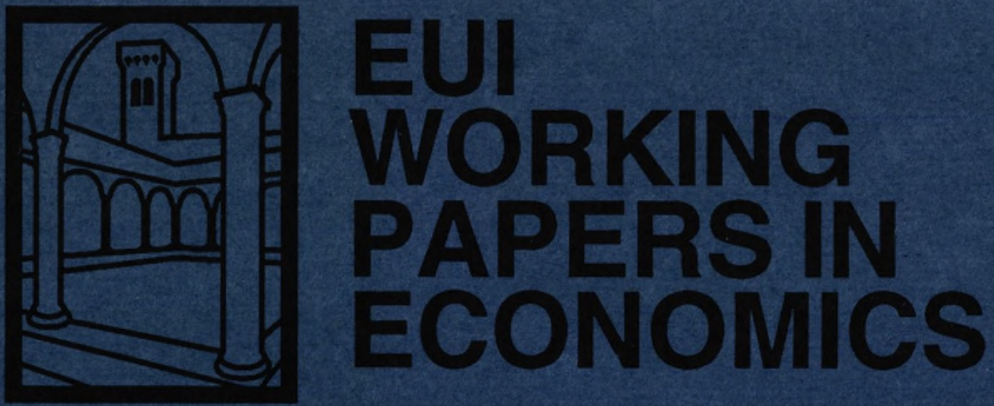

EUI Working Paper ECO No. 93/19

Use and Misuse of Unobserved Components in Economic Forecasting

AGUSTÍN MARAVALL 

individually (e.g. EUI Working Paper LAW No. 90/1). 


\section{EUROPEAN UNIVERSITY INSTITUTE, FLORENCE ECONOMICS DEPARTMENT}

EUI Working Paper ECO No. 93/19

Use and Misuse of Unobserved Components in Economic Forecasting AGUSTÍN MARAVALL 
All rights reserved.

No part of this paper may be reproduced in any form without permission of the author.

(C) Agustín Maravall

Printed in Italy in March 1993

European University Institute

Badia Fiesolana

I - 50016 San Domenico (FI)

Italy 


\title{
Use and Misuse of Unobserved Components in Economic Forecasting
}

\author{
Agustín Maravall* \\ European University Institute
}

January 1993

\begin{abstract}
The paper deals with unobserved components in economic time series within a general model-based approach. The component, its final estimator, and the preliminary one (which also includes the forecast) are seen to follow different ARIMA models, which can be expressed in terms of the series innovations. Analytical expressions are derived for the different types of associated errors.

Two applications are presented. The first one shows how the use of unobserved components can increase substantially forecasting precision, and how the model-based approach can rigorously answer questions of applied concern. The second application illustrates the dangers of using unobserved components in some macroeconomic models. It is first shown how unobserved component estimators, such as for example a series seasonally adjusted with X11 or with a model-based procedure, will most likely be noninvertible, and hence invertible models (for example, a VAR model) are not appropriate for them. Second, the recent Stock and Watson model aimed at forecasting recessions is used to illustrate how probabilities computed over the distribution of the component, of its final estimator, and of its preliminary one will be poor estimators of each other. As a consequence, the recession forecasts will be systematically biased.
\end{abstract}

${ }^{*}$ Department of Economics, European University Institute, Badia Fiesolana, I-50016 S. Domenico di Fiesole (FI), Italy, Tel.: +39-55-5092.347, Fax: +39-55-5092.202, E-mail: Maravall@bf.eui.it 


\section{Introduction}

The evolution of economic time series is subject to a variety of short-term movements that may provide a distorted view of the underlying growth of a variable of interest. Typical examples of such movements are the seasonal fluctuations, and the transitory and erratic movements that tend to cancel out over relatively short periods (i.e., the short-term noise). Since a seasonal or a noise component are never directly observed, the relevant underlying growth of the series is, as a consequence, an unobserved component (i.e., a "signal"). Typical signals are, for instance, the Seasonally Adjusted (SA) series or the trend component.

Therefore, interest in obtaining a less distorted view of how the economy is evolving leads to interest in unobserved components and, naturally, their forecasts. In this paper I address the issue of unobserved components and their forecasts within a modelbased approach: the components, and hence the observed series, are outcomes of linear stochastic processes which shall be parametrized as Autoregressive Integrated Moving Average (ARIMA) models.

In section 1 the basic unobserved components model is presented, as well as the main assumptions, and section 2 discusses optimal estimators and forecasts of the signal of interest. The properties of the estimators and forecasts, and in particular the structure of their Mean Squared Error (MSE) are analysed in section 3. Section 4 contains a straightforward application, where forecasts of different signals are compared, and it is seen how it is possible to obtain a substantial improvement in forecasting precision. It is further seen how the results in sections 2 and 3 can provide solutions to several problems of applied interest.

The distinction between the theoretical unobserved component, its final or historical estimator, and the preliminary estimator (and forecast), is often a source of confusion in applied work. Section 5 discusses some of the dangers associated with not modeling the distinction properly. The discussion is illustrated with a model similar to that recently developed by Stock and Watson to analyse and forecast the business cycle; it is also seen how the results are easily extended to other important types of models. Finally, section 6 contains a summary of the results.

\section{The Model and Assumptions}

Let $x_{t}$ be a time series which is the sum of a signal $m_{t}$, and a nonsignal component $n_{t}$, as in

$$
x_{t}=m_{t}+n_{t},
$$

where the two components are outcomes of ARIMA models, which we write in short as

$$
\phi_{m}(B) m_{t}=\theta_{m}(B) b_{t}
$$




$$
\phi_{n}(B) n_{t}=\theta_{n}(B) c_{t} ;
$$

$B$ denotes the lag operator, $\phi(B)$ and $\theta(B)$ are finite polynomials in $B$ that may contain unit roots, and $b_{t}$ and $c_{t}$ are orthogonal white-noise variables, with variances $V_{b}$ and $V_{c}$. (Throughout the paper, a white-noise variable denotes a variable that is normally, identically, and independently distributed.) It is assumed that the roots of the autoregressive (AR) polynomials $\phi_{m}(B)$ and $\phi_{n}(B)$ are different; since AR roots for the same frequency should belong to the same component, this is not a restrictive assumption. The two polynomials $\phi_{m}(B)$ and $\theta_{m}(B)$ share no root in common, and the same is true of $\phi_{n}(B)$ and $\theta_{n}(B)$. The paper is mostly aimed at quarterly or monthly data, so that, in terms of $(1,1)$, the signal of interest can be the seasonally adjusted series (in which case the nonsignal is the seasonal component), or the trend (in which case the nonsignal is the sum of the seasonal plus the irregular component).

Combining (1.1), (1.2), and (1.3), it is obtained that

$$
\phi_{m}(B) \phi_{n}(B) x_{t}=\phi_{n}(B) \theta_{m}(B) b_{t}+\phi_{m}(B) \theta_{n}(B) c_{t},
$$

and hence $x_{t}$ also follows an ARIMA model of the type

$$
\phi(B) x_{t}=\theta(B) a_{t},
$$

where $\phi(B)=\phi_{m}(B) \phi_{n}(B)$, and $\theta(B) a_{t}$ is the moving average (MA) process such that

$$
\theta(B) a_{t}=\phi_{n}(B) \theta_{m}(B) b_{t}+\phi_{m}(B) \theta_{n}(B) c_{t},
$$

with $a_{t}$ a white-noise variable with variance $V_{a}$ (see Anderson, 1971, p. 224). Without loss of generality, $V_{a}$ is set equal to 1 , so that the variances of the component innovations will be implicitly expressed as fractions of $V_{a}$, the variance of the one-period-ahead forecast error for the observed series. Since the sum of two uncorrelated MA processes [as in (1.5)] can only be noninvertible when the same unit root is shared by both MA polynomials, if we further assume that $\theta_{m}(B)$ and $\theta_{n}(B)$ have no common unit root, it follows that model (1.4) will be invertible. On the other hand, given that the concept of a trend or a seasonal component is intimately linked to nonstationary behavior, models (1.2) and (1.3) will typically be nonstationary (see Hillmer, Bell, and Tiao, 1983). We shall still use the representation

$$
\psi(B)=\theta(B) / \phi(B)
$$

when the series is nonstationary, and similarly for $\psi_{m}(B)$. Further, letting $\omega$ denote frequency (in radians), the Fourier transform of $\psi(B) \psi(F) V_{a}$, where $F=B^{-1}$ is the forward operator, will be referred to as the spectrum of $x_{t}, g_{x}(\omega)$ (for nonstationary series, it is often called the "pseudospectrum"; see Hillmer and Tiao, 1982, or Harvey, 1990). In a similar way, $g_{m}(\omega)$ will denote the spectrum of the signal.

Identification of the models (1.2), (1.3), and (1.4) can be reached in several ways. Broadly, two basic approaches can be distinguished: the so-called ARIMA-Model-Based 
approach (important references are Burman, 1980, and Hillmer and Tiao, 1982), and the Structural Time Series approach (important references are Engle, 1978, and Harvey and Todd, 1983). Since observations are only available on $x_{t}$, the first approach starts with model (1.4), which can be identified and estimated directly from the data using Box-Jenkins techniques; then, derives the models for the signal that are compatible with (1.4). From the set of all admissible models, some additional requirements permit the selection of a unique one. The second approach proceeds in an inverse manner, by identifying a-priori models (1.2) and (1.3) for the components. Ultimately, since (1.2) and (1.3) imply a model of the type (1.4), both approaches are closely linked; in fact, the results in this paper are valid for both approaches, and do not depend on the particular identification restrictions used in order to specify models (1.2) and (1.3).

\section{Optimal Estimation and Forecasting of an Unob- served Component}

Given that the signal is never observed, one is forced to use an estimator. For known models (an assumption that will be made throughout the paper), and having available a finite realization of the series $X_{T}=\left[x_{1}, \ldots, x_{T}\right]$, the signal estimator is given by the conditional expectation

$$
\hat{m}_{t \mid T}=E\left(m_{t} \mid X_{T}\right),
$$

which, under our assumptions, yields the Minimum Mean Squared Error (MMSE) estimator. When $t<T,(2.1)$ provides an estimator of a past signal; when $t=T,(2.1)$ is the concurrent estimator of the signal, and when $t>T, \quad \hat{m}_{t \mid T}$ is the $(t-T)$-periods-ahead forecast. The analytical treatment of these different types of estimators is the same; I shall nevertheless focuss attention on the signal forecast.

It is well known that the conditional expectation (2.1) can be efficiently computed with the Kalman filter (see, for example, Harvey, 1989). For our purposes, however, it will prove more useful to work with an alternative representation of the conditional expectation, namely, the Wiener-Kolmogorov (WK) filter, particularly suited for analytical discussion. In order to derive the WK filter consider, first, the case of an infinite realization of the series $x_{t}$, to be denoted $X$. The optimal estimator of the signal

$$
\hat{m}_{t}=\hat{m}_{t \mid \infty}=E\left(m_{t} \mid X\right)
$$

can then be expressed, using the notation (1.6), as

$$
\hat{m}_{t}=V_{b} \frac{\psi_{m}(B) \psi_{m}(F)}{\psi(B) \psi(F)} x_{t} .
$$

Replacing the $\psi$-polynomials by their rational expressions, after cancelling common factor, (2.3) becomes

$$
\hat{m}_{t}=\nu(B, F) x_{t},
$$


where $\nu(B, F)$ is the WK filter, given by

$$
\nu(B, F)=V_{b} \frac{\theta_{m}(B) \phi_{n}(B)}{\theta(B)} \frac{\theta_{m}(F) \phi_{n}(F)}{\theta(F)} .
$$

(see, for example, Whittle, 1963, and Cleveland and Tiao, 1976). The filter is, thus, centered at $t$, symmetric, and convergent in $B$ and in $F$ due to the invertibility of $\theta(B)$. In fact, (2.5) shows that the WK filter is equal to the autocovariance-generating function of the process

$$
\theta(B) z_{t}=\theta_{m}(B) \phi_{n}(B) b_{t}
$$

(Notice that this process is stationary even when model (1.6) is nonstationary.) Convergence of the filter weights implies that, in practice, the filter can be truncated after a certain point at both ends. To simplify the discussion, we shall assume that the available series is long enough so that, when considering recent estimates, the filter in $B$ has converged. (In practice, this is not a restrictive assumption.)

To project $m_{t}$ on a finite realization $X_{T}$, since $X_{T} \subset X$, by a well-known property of conditional expectations,

$$
\begin{aligned}
\hat{m}_{t \mid T} & =E\left(m_{t} \mid X_{T}\right)=E\left(E\left(m_{t} \mid X\right) \mid X_{T}\right)= \\
& =E\left(\hat{m}_{t} \mid X_{T}\right),
\end{aligned}
$$

which implies that $\hat{m}_{t \mid T}$ can be expressed as

$$
\hat{m}_{t \mid T}=\nu(B, F) x_{t \mid T}
$$

where $\nu(B, F)$ is the WK filter given by $(2.5)$, and

$$
x_{t \mid T}=E\left(x_{t} \mid X_{T}\right) .
$$

Since $x_{t \mid T}$ is the forecast of $x_{t}$ done at time $T$ (equal to $x_{t}$ if $T \geq t$ ), the estimator (2.7) can be seen as the WK filter applied to the available series extended at both ends with forecasts and backcasts (i.e., applied to the "extended series"). For a large enough (positive) $T-t,(2.7)$ provides in practice the final or historical estimator of $m_{t}$, equivalent to (2.4). As $t$ approaches $T$, (2.7) provides preliminary estimators of recent signals; for $t>T,(2.7)$ yields the $(t-T)$-periods-ahead forecast of the signal.

Given an overall ARIMA model (1.4) for the observed series, the polynomials $\phi_{m}(B)$ and $\phi_{n}(B)$ are immediately obtained by factorizing $\phi(B)$, and assigning the roots to $m_{t}$ or $n_{t}$ according to the type of behavior they induce in the series (i.e., the frequency with which they are associated). In general, however, the polynomials $\theta_{m}(B)$ and $\theta_{n}(B)$, as well as the variances $V_{b}$ and $V_{c}$, are not uniquely determined. This is easily seen from the following consideration.

Let models (1.2) and (1.3) represent an admissible decomposition of $x_{t}$, with at least one of the components invertible. Let this invertible component be, for example, $m_{t}$, and denote by $g_{m}$ the positive number:

$$
g_{m}=\min g_{m}(\omega), \quad 0 \leq \omega \leq \pi
$$


It follows that $m_{t}$ in (1.2) can be further decomposed into orthogonal signal and noise components, as in

$$
m_{t}=\tilde{m}_{t}+u_{t}
$$

where $u_{t}$ is a white-noise variable with variance equal to any number in the interval $\left[0, g_{m}\right]$. If $u_{t}$ is removed from $m_{t}$ and, consequently, added to $n_{t}$, so that

$$
\tilde{n}_{t}=n_{t}+u_{t}
$$

it is straightforward to find that $\tilde{m}_{t}$ and $\tilde{n}_{t}$ have also expressions of the type (1.2) and (1.3), and, since their spectra will be nonnegative, they provide another admissible decomposition of $x_{t}$. Different admissible decompositions can be obtained by setting $V_{u}$ equal to the different points in the interval $\left[0, g_{m}\right]$ or, in other words, by deciding how much white-noise (within the admissibility bounds) should be assigned to the sig$\mathrm{nal} /$ nonsignal components. (If $n_{t}$ is invertible, an analogous reasoning would apply.) For our purposes, this lack of identification causes no problem. It is true that different admissible decompositions will imply different estimators of the past and concurrent signals. But, since the forecast of independent future white-noise is zero, (2.8) implies that all admissible decompositions will provide the same forecast of the signal.

\section{Mean Squared Estimation and Forecasting Error}

Let the error in the forecast of the signal be

$$
e_{t \mid T}=m_{t}-\hat{m}_{t \mid T}
$$

It can be rewritten as

$$
e_{t \mid T}=\left(m_{t}-\hat{m}_{t}\right)+\left(\hat{m}_{t}-\hat{m}_{t \mid T}\right),
$$

where the first parenthesis in the right-hand-side (r.h.s.) of the equation represents the error in the final estimator

$$
d_{t}=m_{t}-\hat{m}_{t}
$$

and the second parenthesis represents the difference between the final and preliminary estimators. This is the revision error in the preliminary estimator

$$
d_{t \mid T}=\hat{m}_{t}-\hat{m}_{t \mid T}
$$

of course, when $t>T$, this preliminary estimator is the forecast. The structure of the two types of errors (in particular, their variances and covariances) can be easily derived simply from the models for the components in section 1. First, as shown in Pierce (1979), the error in the final estimator, $d_{t}$, and the revision error, $d_{t \mid T}$, are independent, so that

$$
V\left(e_{t \mid T}\right)=V\left(d_{t}\right)+V\left(d_{t \mid T}\right)
$$


Concerning the final estimation error, Pierce further shows that $d_{t}$ can be seen as the output of the stationary model

$$
\theta(B) d_{t}=\theta_{m}(B) \theta_{n}(B) g_{t},
$$

where $g_{t}$ is white noise with variance $V_{g}=V_{b} V_{c} / V_{a}$. Therefore, the variance of $d_{t}$ is finite, and its Autocorrelation Function (ACF) will converge; both, variance and ACF, are immediately obtained from models (1.2), (1.3), and (1.4).

As for the revision error $d_{t \mid T}$, a simple way to derive its properties is the following. Replacing $x_{t}$ in (2.4) with (1.4), the final estimator of the signal can be expressed as a linear filter on the innovations $a_{t}$ of the observed series:

$$
\hat{m}_{t}=\eta(B, F) a_{t},
$$

where, considering (2.5), the filter $\eta(B, F)$ is given by

$$
\eta(B, F)=V_{b} \frac{\theta_{m}(B)}{\phi_{m}(B)} \frac{\theta_{m}(F) \phi_{n}(F)}{\theta(F)} .
$$

The filter will not be convergent in $B$ when $m_{t}$ is nonstationary; however, it will always be convergent in $F$. Assuming some suitable starting conditions (see Bell, 1984), the estimator (3.4) can then be expressed as (for $t>T$ )

$$
\hat{m}_{t}=\eta_{t \mid T}^{(1)}(B) a_{T}+\eta_{t \mid T}^{(2)}(F) a_{T+1}
$$

where

$$
\begin{aligned}
& \eta_{t \mid T}^{(1)}(B)=\eta_{T-t}+\eta_{T-t-1} B+\ldots+\eta_{-t} B^{T} \\
& \eta_{t \mid T}^{(2)}(F)=\eta_{T-t+1}+\eta_{T-t+2} F+\ldots+\eta_{0} F^{t-T-1}+\ldots
\end{aligned}
$$

The term $\eta_{t \mid T}^{(1)} a_{T}$ represents the effect of the innovations up to (and including) $a_{T}$ on the estimator $\hat{m}_{t}$. From (3.5), the polynomial $\eta_{t \mid T}^{(2)}(F)$ is convergent; further, the $\eta$ coefficients are straightforward to compute, as shown in the Appendix. Since $E_{T} a_{T+k}=$ 0 for $k>0$, applying (2.6) to (3.6), the forecast of the signal is given by

$$
\hat{m}_{t \mid T}=\eta_{t \mid T}^{(1)}(B) a_{T}
$$

and substracting this expression from (3.6), the revision error is found to be

$$
d_{t \mid T}=\eta_{t \mid T}^{(2)}(F) a_{T+1} .
$$

The moving average representation (3.7) can be used to derive the variance and ACF of $d_{t \mid T}$. Invertibility of (1.4) guarantees that the variance will be finite and the ACF will converge.

In summary, the error in forecasting, at period $T$, the signal $m_{t}$ is equal to

$$
e_{t \mid T}=m_{t}-\hat{m}_{t \mid T}=d_{t}+d_{t \mid T},
$$

where $d_{t}$ and $d_{t \mid T}$ are independent. From the autocovariance function of the two, the variance and ACF of $e_{t \mid T}$ is easily computed. Notice that the fact that the variances of $e_{t \mid T}, d_{t}$, and $d_{t \mid T}$ are finite, implies that when the signal is nonstationary, the signal, its final estimator, and its forecast will be pairwise cointegrated. 


\section{An Application}

As an example, consider the Italian monetary aggregate targeted in monetary policy, $M 2$ (kindly provided to me by the Bank of Italy). It is a monthly series with 84 observations, starting in 1985 . The model

$$
\nabla \nabla_{12} x_{t}=\left(1-.634 B^{12}\right) a_{t}
$$

where $\nabla=1-B, \quad \nabla_{12}=1-B^{12}$, and $x=\log M 2$ fits very well the series, and the standard deviation of the innovation is $\sigma_{a}=.00723$.

Model (4.1) accepts a decomposition as in (1.1)-(1.3), with $\phi(B)=\nabla \nabla_{12}$, $\phi_{m}(B)=\nabla^{2}$, and $\phi_{n}(B)=1+B+\ldots+B^{11}$. The last two polynomials represent the trend-type autoregressive unit roots, and the seasonal autoregressive unit roots, respectively. It is found that the identification problem mentioned in section 2 is, in this case, due to the fact that a white-noise component, say $u_{t}$, with variance in the range $\left(0, .179 V_{a}\right)$ can be freely interchanged between the two components $m_{t}$ and $n_{t}$ without violating the admissibility of the decomposition. Consider two particular cases of interest:

(a) The maximum noise variance is assigned to the component $n_{t}$. In this case the signal follows the model

$$
\nabla^{2} m_{t}=\left(1+.04 B-.96 B^{2}\right) b_{t} ; \quad V_{b}=.168 V_{a}
$$

and is equal to the trend component in the ARIMA-model-based approach referred to earlier. (The nonsignal component is the sum of the seasonal and irregular components.)

(b) The maximum noise variance is assigned to the signal $m_{t}$. The model for the signal becomes then

$$
\nabla^{2} m_{t}=\left(1-.97 B+.01 B^{2}\right) b_{t} ; \quad V_{b}=.682 V_{a}
$$

and the signal is the seasonally adjusted series in the ARIMA-model-based approach. Notice that the seasonally adjusted series follows a model very close to the "random walk plus drift" specification. The nonsignal component is in this case simply the seasonal component. Within the set of admissible specifications for the signal, cases (a) and (b) represent two extreme cases: the trend (model (4.2)) and the seasonally adjusted series (model (4.3)) provide the smoothest and the noisiest signal, respectively.

Monetary policy provides an important application of unobserved component forecasting. Overwhelmingly, short-term policy formally uses as signal the seasonally adjusted series, and seasonal adjustment is indeed an issue of serious concern. Typically, at the end of the year, the monetary authority forecasts the seasonal factors or components 
for the next year. These factors will be used in control and monitoring of the monetary aggregate, in order to accomodate the supply of money to the seasonal fluctuation in money demand, avoiding thus seasonal fluctuations in interest rates. The standard procedure to forecast the seasonal factors is to apply an "ad hoc" formula (as in X11 or X11 ARIMA), with no underlying standard error associated with the forecast.

The actual practice of seasonal adjustment in the conduct of monetary policy has been questioned on several occasions. In fact it has been suggested that the trend should play a more important role (Box et al., 1987, Kenny and Durbin, 1982, Maravall and Pierce, 1986, Moore et al., 1981). One reason, among several, that may make the trend an attractive signal is that, due to its more stable behavior, it could be forecasted with more precision.

Applying the results of the previous section to model (4.1) and the two specifications ((4.2) and (4.3)) for the signal, it is straightforward to obtain the precision of the different forecasts. The standard errors of the 1- and 6-month-ahead forecasts of the $M 2$ series (in logs), of its trend, and of its seasonally adjusted component are compared in the following table:

Standard Error of Forecast

(Monetary Aggregate Series)

\begin{tabular}{l|c|c}
\hline & 1-period-ahead & 6-periods-ahead \\
\hline Series & .0072 & .0177 \\
Seas. Adj. Series & .0071 & .0166 \\
Trend & .0066 & .0163 \\
\hline
\end{tabular}

Clearly, for the short-term horizons we consider, the trend outperforms the seasonally adjusted series and the original series in terms of its forecasting accuracy. This relative performance of forecasts is, in fact, found in other important macroeconomic series. The following table gives the same standard errors of the previous table for the Spanish export and import series (in logs) discussed in Maravall (1986):

Standard Error of Forecast

(Foreign Trade Series)

\begin{tabular}{ll|c|c}
\hline & & 1-period-ahead & 6-periods-ahead \\
\hline Series & Exports & .126 & .143 \\
& Imports & .117 & .133 \\
\hline Seas. Adj. Series & Exports & .110 & .129 \\
& Imports & .101 & .127 \\
\hline Trend & Exports & .056 & .088 \\
& Imports & .054 & .083 \\
\hline
\end{tabular}

Since the "true" trend component is never observed, we will never be able to measure the exact forecast error. But if the overall ARIMA models shows no sign of 
misspecification, we can reasonably assume that the (unobservable) forecast error of the trend displays the precision derived from the model. As seen in figure 1 for the export series, a $95 \%$ confidence interval around the trend forecast would be substantially narrower than the corresponding one around the original series forecast (the interval around the SA series would lie in between the two previous ones). Since, in the previous examples, the difference between the trend and the observed series is simply the seasonal component plus random noise (which tends to cancel out over relatively short periods), the relative precision of the trend makes it an attractive candidate for a short-term signal.

Expressions (3.4) and (3.7) - completely determined from the structure of models (1.2), (1.3), and hence (1.4) - allow us to compute, for a given model, the exact standard error of the different signal forecasts. The models derived for $d_{t}$ and $d_{t \mid T}$ provide further answers to a variety of questions of applied interest. For example, rates of growth are typically easier to interpret than levels, and are thus heavily used. From the ACF of $d_{t}, d_{t \mid T}$, and $e_{t \mid T}$, standard errors for the (linear approximations to the) different rates of growth and their forecasts are readily obtained. A closely watched rate, for example, is the annual rate at which money is growing at the present moment, measured as the growth of the signal over the last six months for which there are observations, plus the forecasted growth over the next six months. For the Italian monetary aggregate example, the standard error of the above rate (expressed in percent points) is 1.91 for the original series, 1.88 for the seasonally adjusted ones, and 1.85 for the trend component. Over the larger span implicit in the annual rate, the forecasting improvement from using unobserved components naturally decreases.

The final illustration we mention concerns another problem of applied concern. As mentioned before, the standard operating procedure for the monetary authority is to seasonally adjust once a year, and compute then the seasonal factors to be used during the following year. It is well known that there is a loss in precision with respect to a procedure whereby seasonal adjustment is done concurrently every month, and it is important to know how much precision is lost with the suboptimal procedure. Within the framework of section 3, this loss of precision can be quantified as follows.

In the once-a-year adjustment, the seasonal factors used are $\hat{s}_{t \mid t}, \hat{s}_{t+1 \mid t}, \ldots, \hat{s}_{t+11 \mid t}$; their estimation error can be expressed as

$$
e_{t+j \mid t}=d_{t}+d_{t+j \mid t}, \quad j=0,1, \ldots, 11 .
$$

The variance of $d_{t}$ is, as before, that of model (3.3), and, letting $\eta_{-j}$ denote the coefficient of $B^{j}$ in $\eta(B, F)$ of $(3.4)$, the variance of $d_{t+j \mid t}$ becomes, for $j=0$,

$$
V\left(d_{t \mid t}\right)=\sum_{i=1}^{\infty} \eta_{i}^{2},
$$

a convergent sum, and, for $j=1,2, \ldots, 11$,

$$
V\left(d_{t+j \mid t}\right)=\eta_{-j+1}^{2}+\ldots+\eta_{0}^{2}+V\left(d_{t \mid t}\right) .
$$


For the monetary aggregate series (model (4.1)), operating in this way, and averaging the results for the 12 estimation errors $d_{t \mid t}, \ldots, d_{t+11 \mid t}$, it is found that concurrent adjustment would reduce the root mean-squared error of the seasonal factor estimators by $15.2 \%$, on average. This seems to be a somewhat boundary value: the improvement is certainly not negligible, but neither are the practical requirements of a concurrent seasonal adjustment.

\section{Some Extensions; The Danger of Using Unob- served Components}

\subsection{The Basic Model}

In the previous section I have illustrated some straightforward applications of unobserved components forecasting. However, when used in econometric models, the distinction between the theoretical unobserved component, its final estimator, and the preliminary one is often a source of confusion in applied work. Since one is always forced to work with estimators, lack of a proper consideration of the different stochastic structures may have serious effects. I shall address two types of effects, one related to the specification of the models; the second one related to probability statements concerning the distribution of the unobserved components.

The two types of complications appear in the important work that Stock and Watson have recently completed, aimed at analysing the business cycle and forecasting recessions (see Stock and Watson, 1989, 1991, 1993). Thus, in what follows, I shall maintain their framework and use for illustration a particularly simple case of their model. Leaving aside constants and leading indicators, which are irrelevant to our discussion, the model can be expressed as

$$
\begin{aligned}
\nabla x_{t} & =\gamma(B) \nabla c_{t}+u_{t}, \\
\phi(B) \nabla c_{t} & =b_{t} \\
D(B) u_{t} & =\omega_{t}
\end{aligned}
$$

where $x_{t}$ is a vector of $k$ observed economic variables, $c_{t}$ is a scalar unobserved component that follows model (5.1.b), and $u_{t}$ is a vector of $k$ residuals, assumed to follow the VAR model (5.1.c). The polynomial $\phi(B)$ is stationary, and so is the polynomial matrix $D(B)$. The residuals $b_{t}$ and $\omega_{t}$ are mutually independent white-noise variables, Normally distributed, with zero mean, and variances $V_{b}$ and $V_{\omega}$, respectively. (While $c_{t}$ is a scalar $\mathrm{I}(1)$ variable, $u_{t}$ contains $k \mathrm{I}(0)$ variables.) The elements in the vector $x_{t}$ share the common nonstationary component $c_{t}$, and hence $x_{t}$ is the sum of an effect due to the common factor, plus a VAR model. Notice that the specification rules out the possibility of cointegration among the $x$-variables, since, in such a case, it is easily seen that $u_{t}$ could not follow a finite VAR model as in (5.1.c). 


\subsection{Invertible Models and Seasonally Adjusted Series}

In the Stock and Watson (SW) model, some of the variables in the $x_{t}$ vector have been seasonally adjusted with X11. Properly speaking, thus, some of the variables in $x_{t}$ are not observed variables, but estimators of an unobserved component (the SA series). Although the distinction is often ignored in applied econometric work, it is in no way trivial, and may have strong implications in terms of the model specification, as I proceed to show.

Leaving aside the preliminary seasonally adjusted series at both ends of the series, for the historical estimator, the SA series obtained with X11 (ignoring outlier corrections) can be expressed as the linear filter

$$
x_{t}^{a}=\nu_{X 11}(B, F) x_{t}
$$

where $\nu_{X 11}(B, F)$ is centered and symmetric. Ghysels and Perron (1993) present the weights (up to 68 leads and lags) of the linear X11 monthly filter. The Fourier Transform of the filter is displayed in figure 2. The zeroes for the seasonal frequencies correspond to seasonal unit roots and, in fact, factorizing the filter, it is found that the seasonal unit roots appear in duplicate, and the X11 filter can be written as

$$
\nu_{X 11}(B, F)=\alpha(B, F) S(B) S(F),
$$

where $\alpha(B, F)$ is a finite linear filter (centered and symmetric, with decaying weights, as shown in figure 3 ) and

$$
S(B)=1+B+\ldots+B^{11}
$$

contains the seasonal unit roots for the $1,2, \ldots, 6$ times-a-year frequency. Expression (5.3) also applies to the filters implied by the model-based approximation to X11 of Cleveland and Tiao (1976), and Burridge and Wallis (1984). Since, in both modelizations, the seasonal component contains the autoregressive operator $S(B)$, in both cases $\phi_{n}(B)=S(B)$, and hence the seasonal adjustment filter, given by (2.5), has a factorization as in (5.3).

The series for which seasonal adjustment by X11 is appropriate are typically series with nonstationary seasonality. In general, thus, the roots of $S(B)$ will be part of their autoregressive polynomial, so that the model for the original series can be, quite generally, written as

$$
\delta(B) S(B) x_{t}=\lambda(B) a_{t},
$$

where $\delta(B)$ is the nonseasonal autoregressive nonstationary polynomial (typically $\nabla$ or $\left.\nabla^{2}\right)$, and $\lambda(B) a_{t}$ is a stationary process. From (5.2), (5.3), and (5.4), it is obtained that

$$
\delta(B) x_{t}^{a}=\alpha(B, F) S(F) \lambda(B) a_{t} .
$$

This is the model that generates the SA series from the set of innovations $\left[a_{t}\right]$. Since $\alpha(B, F)$ and $\lambda(B)$ are convergent polynomials, they cannot contain the inverse of any 
of the roots of $S(F)$, which are all of unit modulus. As a consequence, $x_{t}^{a}$ will be a noninvertible series, with (at least) 11 unit roots in its moving average expression. (If the seasonality of $x_{t}$ is assumed stationary, then the polynomial $S(B)$ in the r.h.s. of (5.3) does not cancel out, and there will be at least 22 unit roots present!)

When the SA series is used, SW model (5.1.a) is

$$
\nabla x_{t}^{a}=\gamma(B) \nabla c_{t}+u_{t}
$$

where $D(B) u_{t}=\omega_{t}$, so that $u_{t}$ is an invertible process. Since the two components in the r.h.s. of (5.6) are independent and at least one is invertible, it follows that the r.h.s. of (5.6) is an invertible process. But this cannot be true of the left-hand-side, since $x_{t}^{a}$ is noninvertible. As a consequence, SW model cannot be applied to seasonally adjusted series with X11.

At a more basic level, since the SA series are noninvertible, no finite autoregressive representation will capture their structure, nor will it be admissible, of course, to fit a vector autoregression to a set of series some of them seasonally adjusted. The use of autoregressive models on series adjusted with X11 is, however, a common practice.

If instead of seasonally adjusting with X11, the model-based approach of sections 2 and 3 is used, a similar result is obtained. Letting $m_{t}$ in (1.1) denote the SA series and $n_{t}$ the seasonal component, expressions (3.4) and (3.5) imply that the MMSE estimator of the SA series can be seen as the output of the model:

$$
\left[\theta(F) \phi_{m}(B)\right] \hat{m}_{t}=\left[V_{b} \theta_{m}(B) \theta_{m}(F) \phi_{n}(F)\right] a_{t} .
$$

Therefore $\hat{m}_{t}$ will be noninvertible if the seasonal component has unit AR roots (also, if $\theta_{m}(B)$ has unit roots). Since practically all model-based approaches specify a seasonal component with $S(B)$ included in $\phi_{n}(B)$, the SA series obtained with a model-based procedure will likely be noninvertible.

From the previous discussion it is seen that noninvertibility of the SA series is the result of requiring that the sum of the seasonal component over a year span should not be too far from zero (or, in other words, that $S(B) s_{t}$ be a stationary process). Given that this requirement seems a minimal requirement for any seasonal adjustment method (of a moving-average type), noninvertibility of the SA series seems a fairly general property. (For a similar result concerning the trend component, see Maravall, 1993.)

From a more general perspective, what expression (5.7) indicates is that the estimator of a signal (be that an SA series, a trend, or a cycle) will be noninvertible whenever the nonsignal component contains nonstationarity. When this happens, invertible models (such as the SW model or a VAR model) fitted to the signal estimator will be misspecified. 


\subsection{Sequences of Unobserved Components and Forecasting Recessions}

Leaving aside intercepts and leading indicators, Stock and Watson (1993) use model (5.1) to forecast recessions. In brief, with model (5.1) as the data-generating process, they define first a recessionary pattern as a sequence of $\nabla c_{t}$ (the monthly growth of the common unobserved component) that are below a certain threshold; an expansionary pattern is a sequence of $\nabla c_{t}$ above some threshold values. The economy is in a recession in month $t$ if (and only if) that month belongs to a recessionary pattern. In that case, the variable $R_{t}$ takes the value 1 ; otherwise, $R_{t}=0$. Similarly, the variable $E_{t}$ takes the value 1 when month $t$ falls in an expansionary pattern, and $E_{t}=0$ otherwise. To forecast a recession, SW estimate the probability that, for some future $t, R_{t}=1$, conditional on the present information. This probability is estimated by Monte Carlo simulation in the foliowing way:

Suppose information is available up to period $T(t>T)$. SW consider the joint distribution of a sequence $M_{t}=\left[\nabla c_{t-k_{1}}, \ldots, \nabla c_{t}, \ldots, \nabla c_{t+k_{2}}\right]$ conditional on information through month $T$. Thus, they consider the joint distribution of the preiliminary estimator $\hat{M}_{t \mid T}$. Then, preudo-random realizations are drawn from that distribution, and $R_{t}$ and $E_{t}$ are computed for each realization. The probability of a recession is estimated as the number of times $R_{t}=1$ divided by the number of times $R_{t}$ and $E_{t}$ are 1 over all realizations.

The probability that a future $\Delta c_{t}$ falls into a recessionary pattern depends on the joint distribution of the sequence $M_{t}$. This is obvious from the following consideration: When the recessions tend to be very long and the expansions very short, the probability of a future $\Delta c_{t}$ falling into a recessionary pattern will be larger than when recessions are very short and expansions very long. This probability, as already mentioned, is measured by SW over the distribution of the preliminary estimator $\hat{M}_{t \mid T}$.

The authors match the in-sample (and a few out-of-sample) forecasts of their model with the official dating of recessions by the NBER Business Cycle Dating Committee (BCDC). If their model has nothing to do with the way in which the BCDC proceeds, then good performance of the SW forecast would be a product of luck. This is unlikely; as the authors state, their model "attempts to capture, in a simple way, the institutional process in which recessions are categorized" by the BCDC, and they certainly develop an attractive framework for analysing recessions. Yet the use of the unobserved component $c_{t}$ brings a point that casts some doubts as to the proper relationship between their definition of a recession, the way the recession probabilities are estimated, and the actual dating of recessions by the BCDC.

Assume the most favorable case, in which the SW model exactly duplicates the BCDC behavior. In that case, the definition of a recession would be based on the "true" unobserved component, the recession forecast on the preliminary estimators of the component, while the $\mathrm{BCDC}$ measurements would be based on the (optimal) final estimator. Concerning this last assumption it is worth mentioning that indeed the BCDC identifies 
recessions with a two-sided filter, characteristic of final estimators. Thus, for example, the BCDC reported on December 22, 1992, the dating of the last official recession: it had started in July 1990, and had ended in March 1991. It took, thus, the BCDC 21 periods after the recession ended to reach the final "official" estimator. (This behavior is clearly rational: after all, what the $\mathrm{BCDC}$ does is to look at observations and extract some type of stochastic signal. It would not make sense to stick to an old preliminary estimator when new evidence points to a revision.)

While it is true that the final estimator is the best estimator of the unobserved component when all relevant information has become available, and that the preliminary estimator is the best estimator of the component (and of its final estimator) when part of the information is still not available, the distribution functions of the unobserved component, of the final estimator, and of the preliminary estimator will be (structurally) different. As a consequence, measures of probability computed over those distributions can be poor estimators of each other.

To illustrate the point it will be enough to consider the simplest (nontrivial) case of model (5.1), namely the one given by

$$
\begin{aligned}
\nabla x_{t} & =\nabla c_{t}+u_{t} \\
(1-\phi B) \nabla c_{t} & =b_{t},
\end{aligned}
$$

where $u_{t}$ and $b_{t}$ are independent white-noise variables with variances $V_{u}$ and $V_{b}$, respectively. By defining $z_{t}=\nabla x_{t}$, and $m_{t}=\nabla c_{t}$, the previous model can be rewritten

$$
\begin{aligned}
z_{t} & =m_{t}+u_{t} \\
(1-\phi B) m_{t} & =b_{t} .
\end{aligned}
$$

Model (5.8) is a simple "signal-plus-noise" decomposition, with the signal following a stationary $\mathrm{AR}(1)$ process. It is easily seen that (5.8) implies that the observed series follows an $\operatorname{Arma}(1,1)$ model of the type

$$
(1-\phi B) z_{t}=(1-\theta B) a_{t}
$$

where $(1-\theta B) a_{t}$ is the invertible MA(1) process such that its autocovariance function is that of $\left[b_{t}+(1-\phi B) u_{t}\right]$. The parameters $\theta$ and $V_{a}$ are easily obtained from $V_{u}, V_{b}$, and $\phi$.

For this simplified model, define a recession as two consecutive negative values of the signal. Consider an infinite realization of the process $\nabla c_{t}=m_{t}$, as well as the corresponding series of final estimators $\hat{m}_{t}$, and of preliminary estimators $\hat{m}_{t+k \mid t}$, for some positive value of $k$. Let us ask ourselves the question: what is the probability that $m_{t}$ and $m_{t-1}$ are both negative? This probability is easily obtained from model (5.8). According to it

$$
\left(\begin{array}{l}
m_{t} \\
m_{t-1}
\end{array}\right) \sim N\left[\underline{0}, V_{m}\left(\begin{array}{ll}
1 & \phi \\
\phi & 1
\end{array}\right)\right]
$$


where $V_{m}=V_{b} /\left(1-\phi^{2}\right)$. From this joint distribution, $P\left(m_{t}<0, m_{t-1}<0\right)$ is readily obtained.

The distribution (5.9) of the unobserved component concerns the definition of a recession. The $\mathrm{BCDC}$ however never observes the component and is forced to use its optimal estimator when all relevant data has been observed, i.e. $\hat{m}_{t}$. So, let us ask now the question: what is the probability that $\hat{m}_{t}$ and $\hat{m}_{t-1}$ be both negative? To compute it, notice that equation (5.7) becomes, for the particular case of model (5.8),

$$
(1-\phi B)(1-\theta F) \hat{m}_{t}=V_{b} a_{t},
$$

from which the autocovariances of $\hat{m}_{t}$ are easily obtained. The joint distribution of the final estimators $\hat{m}_{t}$ and $\hat{m}_{t-1}$ is

$$
\left(\begin{array}{l}
\hat{m}_{t} \\
\hat{m}_{t-1}
\end{array}\right) \sim N\left[\underline{0}, V_{f}\left(\begin{array}{ll}
1 & r \\
r & 1
\end{array}\right)\right],
$$

where $r=(\phi+\theta) /(1+\phi \theta)$, and $V_{f}=(1+\phi \theta) V_{b}^{2} V_{a} /\left[(1-\phi \theta)\left(1-\phi^{2}\right)\left(1-\theta^{2}\right)\right]$. From (5.11), one can obtain $P\left(\hat{m}_{t}<0, \hat{m}_{t-1}<0\right)$.

Finally, the recession forecasts are based on the joint distribution of the preliminary estimator $\hat{m}_{t+k \mid t}$, for $k>0$. Again, let us ask the question: what is the probability that the preliminary estimators of two consecutive monthly growths $\left(\hat{m}_{t+k \mid t}\right.$ and $\left.\hat{m}_{t+k-1 \mid t}\right)$ be both negative? In order to derive the appropriate distribution, notice first that, from (5.10), $\hat{m}_{t+k}$ can be expressed as

$$
\hat{m}_{t+k}=\eta(B, F) a_{t+k},
$$

where

$$
\eta(B, F)=\ldots+\eta_{-1} B+\eta_{0}+\eta_{1} F+\ldots=(1-\phi B)^{-1}(1-\theta F)^{-1}
$$

Hence

$$
\hat{m}_{t+k \mid t}=E_{t} \hat{m}_{t+k}=\eta_{-k} a_{t}+\eta_{-k-1} a_{t-1}+\ldots,
$$

where use has been made of the fact that $E_{t} a_{t+j}=0$ for $j>0$. It is straightforward to find that, for $k>0$,

$$
\eta_{-k}=\frac{\phi^{k}}{1-\theta \phi} V_{b}
$$

so that $\eta_{-k-1}=\phi \eta_{-k}$. Therefore, from (5.12),

$$
\begin{aligned}
\hat{m}_{t+k \mid t} & =\eta_{-k}\left[a_{t}+\phi a_{t-1}+\phi^{2} a_{t-2}+\ldots\right]= \\
& =\frac{\phi^{k} V_{b}}{1-\theta \phi} \frac{1}{1-\phi B} a_{t},
\end{aligned}
$$

and hence the preliminary estimator follows the model

$$
(1-\phi B) \hat{m}_{t+k \mid t}=c_{o} a_{t},
$$


where $c_{0}=\phi^{k} V_{b} /(1-\theta \phi)$ and $B$ operates on $t$. (Notice that the ACF of the component forecast will be closer to that of the true component than the ACF of the final estimator.) Replacing $k$ by $(k-1)$, it is finally obtained that

$$
\hat{m}_{t+k \mid t}=\phi \hat{m}_{t+k-1 \mid t} .
$$

As a consequence, the joint distribution of $\hat{m}_{t+k \mid t}$ and $\hat{m}_{t+k-1 \mid t}$ is degenerate; the correlation between the two preliminary estimators is 1 , and hence

$$
P\left(\hat{m}_{t+k \mid t}<0, \hat{m}_{t+k-1 \mid t}<0\right)=P\left(\hat{m}_{t+k \mid t}<0\right)=.5 .
$$

This probability is constant, independent of the model parameters.

In summary, the probability of a recession, as measured by the unobserved component (according to the definition), by the final estimator (as the official dating committee supposedly does), or by the preliminary estimator (used for forecasting purposes), are structurally different. This is so because they are measured over different distributions, as shown in figure 4, where the same scale is used for both distributions. For example, for the model with parameter values $V_{u}=1, V_{b}=.1, \phi=-.6$, the three probabilities are

$$
\begin{aligned}
P\left(m_{t}<0, m_{t-1}<0\right) & =.15 \\
P\left(\hat{m}_{t}<0, \hat{m}_{t-1}<0\right) & =.08 \\
P\left(\hat{m}_{t \mid t-k}, \hat{m}_{t-1 \mid t-k}\right) & =.50
\end{aligned}
$$

for $k>0$. If the sign of $\phi$ is reversed, the above probabilities become $.35, .42$, and .50 , respectively. For any given model, thus, probabilities computed over the joint distribution of the preliminary estimator would provide a biased forecast of the underlying probabilities for the true unobserved component or for its final estimator. Figure 5 compares the three types of probability for $V_{b} / V_{u}=.1$ and different values of $\phi$. Even in this very simple case of a stationary AR(1) signal with added noise, the three types of probability can be quite distant.

In particular, in model (5.8), since (5.14) holds for any $k$, the probability of a recession computed over the joint distribution of the forecasts (equal to .5 in all cases) is always larger than that probability computed over the joint distribution of the final estimators. In other words, for any forecast horizon, the probabilty given by the forecasts will overestimate the probability in the official dating. It is worth noticing that SW find precisely the same bias: the forecasted probability tends to be larger than the one obtained from the BCDC classification, for all forecast horizons.

The example we have discussed has focussed on the joint distribution of the signal and of its estimator. A similar result can be derived for the conditional distribution of the unobserved component. To illustrate it, consider a slightly different version of the previous model, often used to analyse business cycles in macroeconomic (see, for example, Stock and Watson, 1988, Clark, 1987, and Watson, 1986). The observed series is assumed equal to the sum of a trend component, which follows a random-walk process, 
and an orthogonal stationary process, which represents the business cycle. As before, it will be enough to consider the simplest case, given by

$$
\begin{aligned}
x_{t} & =m_{t}+u_{t} \\
\nabla m_{t} & =b_{t} .
\end{aligned}
$$

where $m_{t}$ is the nonstationary trend, and $u_{t}$ is a white-noise variable, orthogonal to $b_{t}$. Model (5.15) implies that $x_{t}$ follows an IMA $(1,1)$ model

$$
\nabla x_{t}=(1-\theta B) a_{t}, \quad(\theta>0),
$$

where $(1-\theta B) a_{t}=b_{t}+(1-B) u_{t}$.

Since $u_{t}$ is white-noise, $P\left(u_{t}<0 \mid u_{t-1}<0\right)=.5$. As for the MMSE estimator $\hat{u}_{t}$, for a full realization of the series, from (5.7) it is seen that $\hat{u}_{t}$ follows the model

$$
(1-\theta F) \hat{u}_{t}=V_{u}(1-F) a_{t},
$$

so that its ACF is that of the inverse or dual model of (5.16). Expression (5.17) implies that $\left(\hat{u}_{t}, \hat{u}_{t-1}\right)$ have a joint distribution as in (5.11), with $r=(\theta-1) / 2$, and $V_{f}=$ $2 V_{u}^{2} V_{a} /(1+\theta)$; from that, the probability of interest can be easily computed. For the case $V_{u}=.1, V_{b}=1$, it is obtained that

$$
P\left(\hat{u}_{t}<0 \mid \hat{u}_{t-1}<0\right)=.35 \text {, }
$$

certainly different from the value of .5 obtained for the unobserved component. As before, the use of the distribution of the MMSE estimator induces a bias in the computed probability. In this case, the probability associated with the definition of a recession (i.e., with the unobserved component) would be underestimated. Figure 6 compares the conditional distribution of the component and of its estimator.

\section{Summary}

The paper analyses unobserved component (or signal) forecasting within a model-based approach, whereby the unobserved components (and hence the observed series) follow ARIMA processes. The model approach, described in section 1, is quite general and, in particular, is valid for the so-called ArImA-Model-Based and Structural Time Series metodologies.

In section 2 the optimal estimator and forecasts of the unobserved component are derived. The forecast can be seen as a preliminary estimator, which shall be revised until the final or historical estimator is obtained. The preliminary and final estimators are expressed in terms of the Wiener-Kolmogorov filter, and as filters applied to the innovations of the observed series. It is seen that the distribution function of the theoretical component will be different from that of the final estimator, which in turn will differ from that of the preliminary one. In section 3, analytical expressions are derived 
for the error in the final estimator (i.e., the difference between the unobserved component and its final estimator), and for the revision error (i.e., the difference between the preliminary estimator and the final one). Both types of errors are seen to be stationary processes, determined from the overall model, and computation of their variances and autocovariances is straightforward.

Section 4 contains an application to the monthly series of the Italian money supply. Models for alternative short-term signals (in particular, the seasonally adjusted series and the trend) are derived. It is found that the use of the trend may produce a substantial improvement in forecasting precision, and that this is also true for other types of macroeconomic variables. Knowledge of the models for the errors permits us to answer a variety of questions of applied interest. For example, the precision of the forecast of alternative rates of growth of interest, as measured with different signals, can be readily assessed. As another example, it is possible to quantify the loss in precision implied by a once-a-year seasonal adjustment procedure instead of a concurrent one.

The distinction between the theoretical unobserved component, its final estimator, and the preliminary one, is often a source of confusion in applied work. Section 5 discusses some of the dangers associated with this confusion. The first danger concerns the fitting of models to series seasonally adjusted with X11, instead of using the original unadjusted series. It is shown that the final seasonally adjusted series will be noninvertible, and hence invertible models cannot be used on them. Examples of invertible models are finite autoregressive or VAR models, as well as the model recently developed by Stock and Watson to analyse and forecast the business cycle. Use of invertible models on seasonally adjusted series is, however, a common practice. Using the model-based approach, the same result is obtained: the final seasonally adjusted series will typically be noninvertible. More generally, the final estimator of an unobserved component will be noninvertible whenever some of the other components present in the series is nonstationary.

The second danger discussed concerns bias in inferences drawn from the joint distribution of the unobserved component. The Stock and Watson model referred to above is used as illustration. In this model the probability of a recession depends on the joint distribution of sequences of an unobserved component. While the definition of a recession is based on the theoretical component, the forecasted probability of a recession depends on the conditional distribution of the preliminary estimator. Moreover, the final dating of recessions is based on the final estimator. While it is true that the final and preliminary estimators are the best estimators of the component for a complete and a partial realization of the series, respectively, the distribution function of the component, of the final estimator, and of the preliminary estimator will be structurally different. As a consequence, measures of probability computed over those distributions will be poor estimators of each other and, as shown in the paper, will display systematic bias. This bias also affects the computation of conditional probabilities, as illustrated with a slightly different model (also used by macroeconomists to analyse the business cycle). 


\section{APPENDIX}

\section{Decomposition of a Two-Sided Asymmetric Filter}

The filter (3.5), that expresses the MMSE estimator of the signal in terms of the series innovations, is a two-sided asymmetric filter. Its knowledge, as repeatedly shown in the paper, permits to answer many questions of applied interest. I proceed to sketch a simple procedure to obtain the $\eta$-coefficients and express the filter as the sum of a filter in $B$ and a filter in $F$. Thus, consider, in general, the filter

$$
\eta(B, F)=\frac{N_{1}(B) N_{2}(F)}{D_{1}(B) D_{2}(F)}=\eta^{(1)}(B)+\eta^{(2)}(F) .
$$

From the $N$ - and $D$-polynomials, we wish to obtain the $\eta$-coefficients.

Let $n_{i}$ and $d_{i}$ denote the orders of the polynomials $N_{i}(z)$ and $D_{i}(z)$, respectively $(i=1,2)$. Let $n=n_{1}+n_{2}$, and $d=d_{1}+d_{2}$. The filter (A.1) can be rewritten:

$$
\eta(B, F)=\frac{F^{n_{2}}}{F^{d_{2}}} \frac{N_{1}(B) N_{2}^{\prime}(B)}{D_{1}(B) D_{2}^{\prime}(B)},
$$

where, if $P(z)=p_{0}+p_{1} z+\ldots+p_{r-1} z^{r-1}+p_{r} z^{r}, P^{\prime}(z)$ denotes the polynomial $P^{\prime}(z)=$ $p_{r}+p_{r-1} z+\ldots+p_{1} z^{r-1}+p_{0} z^{r}$. A partial fraction decomposition of the filter in $B$ in the r.h.s. of (A.2) yields

$$
\frac{N_{1}(z) N_{2}^{\prime}(z)}{D_{1}(z) D_{2}^{\prime}(z)}=q(z)+\frac{E(z)}{D_{1}(z)}+\frac{G^{\prime}(z)}{D_{2}^{\prime}(z)},
$$

where the order of $E(z)$ and $G^{\prime}(z)$ are $\left(d_{1}-1\right)$ and $\left(d_{2}-1\right)$, respectively, and the order of $q(z)$ is $(n-d)$ when $n \geq d$ and 0 otherwise. It is easily seen that this decomposition is unique. Compute

then

$$
q(z)+\frac{G^{\prime}(z)}{D_{2}^{\prime}(z)}=\frac{H^{\prime}(z)}{D_{2}^{\prime}(z)}
$$

$$
\frac{N_{1}(z) N_{2}^{\prime}(z)}{D_{1}(z) D_{2}^{\prime}(z)}=\frac{E(z)}{D_{1}(z)}+\frac{H^{\prime}(z)}{D_{2}^{\prime}(z)}
$$

where the order of $H^{\prime}(z)$ is $\left(n-d_{1}\right)$ when $n \geq d$, and $\left(d_{2}-1\right)$ when $n<d$. The coefficients of $E(z)$ and $H^{\prime}(z)$ are easily obtained from the linear system of equations implied by the identity

$$
E(z) D_{2}^{\prime}(z)+H^{\prime}(z) D_{1}(z)=N_{1}(z) N_{2}^{\prime}(z) .
$$

As a consequence,

$$
\begin{aligned}
\eta(B, F) & =\frac{F^{n_{2}}}{F^{d_{2}}}\left[\frac{E(B)}{D_{1}(B)}+\frac{H^{\prime}(B)}{D_{2}^{\prime}(B)}\right]= \\
& =F^{n_{2}-d_{2}} \frac{E(B)}{D_{1}(B)}+F^{n_{2}} \frac{H^{\prime}(B)}{D_{2}(F)}= \\
& =F^{n_{2}-d_{2}} \frac{E(B)}{D_{1}(B)}+F^{r} \frac{H(F)}{D_{2}(F)},
\end{aligned}
$$

where $r=d_{1}-n_{1}$ when $n \geq d$ and $r=n_{2}-d_{2}+1$ when $n<d$. Once the coefficients of the two one-sided filters $E(B) / D_{1}(B)$ and $H(F) / D_{2}(F)$ have been obtained (see, for example, Box, Hillmer and Tiao, 1978, p. 334), each array of coefficients is multiplied by the appropriate power of $F$, as indicated by (A.3), so as to be properly centered. In this way, the desired decomposition (A.1) is obtained. 


\section{References}

Anderson, T.W. (1971), The Statistical Analysis of Time Series, New York: John Wiley.

Bell, W.R. (1984), "Signal Extraction for Nonstationary Time Series", The Annals of Statistics 12, 646-664.

Box, G.E.P., Hillmer, S.C. and Tiao, G.C. (1978), "Analysis and Modeling of Seasonal Time Series", in Zellner, A. (ed.), Seasonal Analysis of Economic Time Series, Washington, D.C.: U.S. Dept. of Commerce - Bureau of the Census, 309-334.

Box, G.E.P., Pierce, D.A. and Newbold, P. (1987), "Estimating Trend and Growth Rates in Seasonal Time Series", Journal of the American Statistical Association 82, 276-282.

Burman, J.P. (1980), "Seasonal Adjustment by Signal Extraction", Journal of the Royal Statistical Society A, 143, 321-337.

Burridge, P. and Wallis, K.F. (1984), "Unobserved Components Models for Seasonal Adjustment Filters", Journal of Business and Economic Statistics 2, 350-359.

Clark, P.K. (1987), "The Cyclical Component of U.S. Economic Activity", The Quarterly Journal of Economics 102, 797-814.

Cleveland, W.P. and Tiao, G.C. (1976), "Decomposition of Seasonal Time Series: A Model for the X-11 Program", Journal of the American Statistical Association 71, 581-587.

ENGLE, R.F. (1978), "Estimating Structural Models of Seasonality", in Zellner, A. (ed.), Seasonal Analysis of Economic Time Series, Washington, D.C.: U.S. Dept. of Commerce - Bureau of the Census, 281-297.

Ghysels, E. and Perron, P. (1993), "The Effect of Seasonal Adjustment Filters on Tests for a Unit Root", Journal of Econometrics 55, 57-98.

Harvey, A.C. (1989), Forecasting, Structural Time Series Models and the Kalman Filter, Cambridge: Cambridge University Press.

Harvey, A.C. and Todd, P.H.J. (1983), "Forecasting Economic Time Series with Structural and Box-Jenkins Models: A Case Study", Journal of Business and Economic Statistics 1, 299-306.

Hillmer, S.C., Bell, W.R. and TiaO, G.C. (1983), "Modeling Considerations in the Seasonal Adjustment of Economic Time Series", in Zellner, A. (ed.), Applied Time Series Analysis of Economic Data, Washington, D.C.: U.S. Department of Commerce - Bureau of the Census, 74-100.

Hillmer, S.C. and TiaO, G.C. (1982), "An Arima-Model Based Approach to Seasonal Adjustment", Journal of the American Statistical Association 77, 63-70. 
Kenny, P. and Durbin, J. (1982), "Local Trend Estimation and Seasonal Adjustment of Economic and Social Time Series", Journal of the Royal Statistical Society A, $145,1-28$.

Maravall, A. (1993), "Stochastic Linear Trends: Models and Estimators", Journal of Econometrics 54, 1-33.

Maravall, A. (1986), "An Application of Model-Based Estimation of Unobserved Components", International Journal of Forecasting 2, 305-318.

Maravall, A. and Pierce, D.A. (1986), "The Transmission of Data Noise into Policy Noise in U.S. Monetary Control", Econometrica 54, 961-979.

Moore, G.H., Box, G.E.P., Kaitz, H.B., Stephenson, J.A. and Zellner, A. (1981), Seasonal Adjustment of the Monetary Aggregates: Report of the Committee of Experts on Seasonal Adjustment Techniques, Washington, D.C.: Board of Governors of the Federal Reserve System.

Pierce, D.A. (1979), "Signal Extraction Error in Nonstationary Time Series", Annals of Statistics 7, 1303-1320.

Stock, J.H. and Watson, M.W. (1993), "A Procedure for Predicting Recessions with Leading Indicators: Econometric Issues and Recent Performance", forthcoming.

Stock, J.H. and Watson, M.W. (1991), "A Probability Model of the Coincident Economic Indicators", in Lahiri, K. and Moore, G.H. (eds.), Leading Economic Indicators: New Approaches and Forecasting Records, Cambridge: Cambridge University Press, 63-85.

Stock, J.H. and Watson, M.W. (1989), "New Indexes of Leading and Coincident Economic Indicators", NBER Macroeconomics Annual, 351-394.

Stock, J.H. and Watson, M.W. (1988), "Variable Trends in Economic Time Series", Journal of Economic Perspectives 2, 147-174.

Watson, M.W. (1986), "Univariate Detrending Methods with Stochastic Trends", Journal of Monetary Economics 18, 49-75.

Whittle, P. (1963), Prediction and Regulation by Linear Least-Squares Methods, London: English Universities Press. 


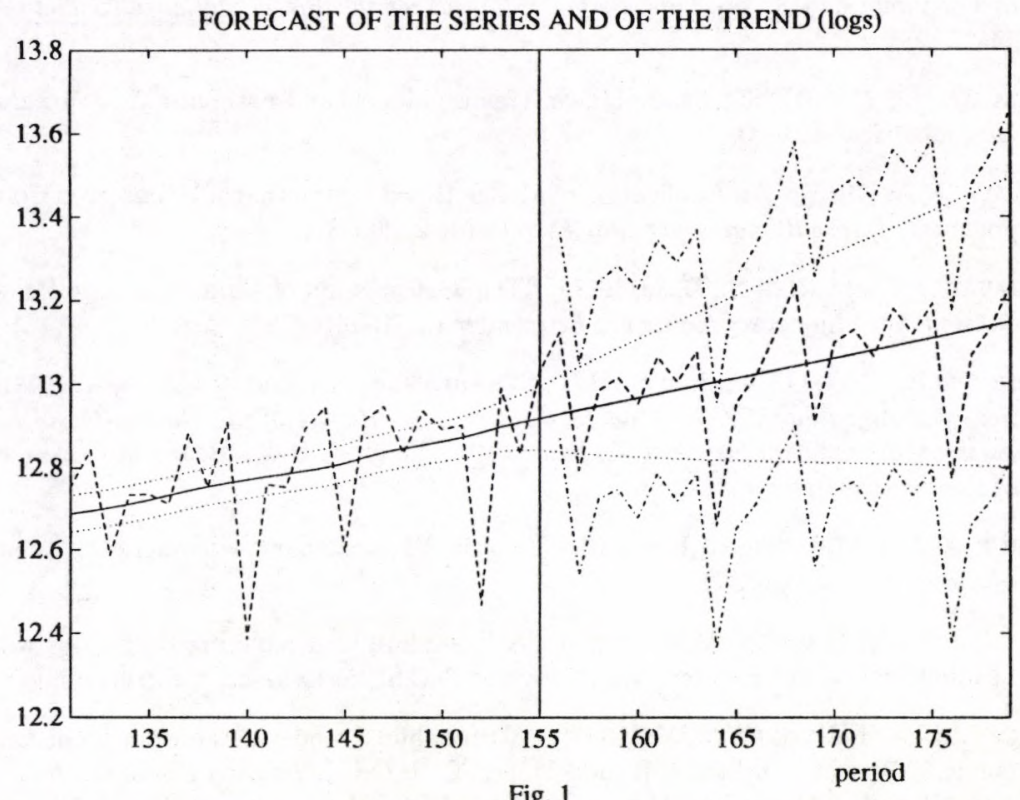

Fig. 1

- - Original Series (last observation for $\mathrm{T}=155$ )

- Trend Component

-.-.- Confidence interval for series forecast function

.... Confidence interval for preliminary estimator of trend 


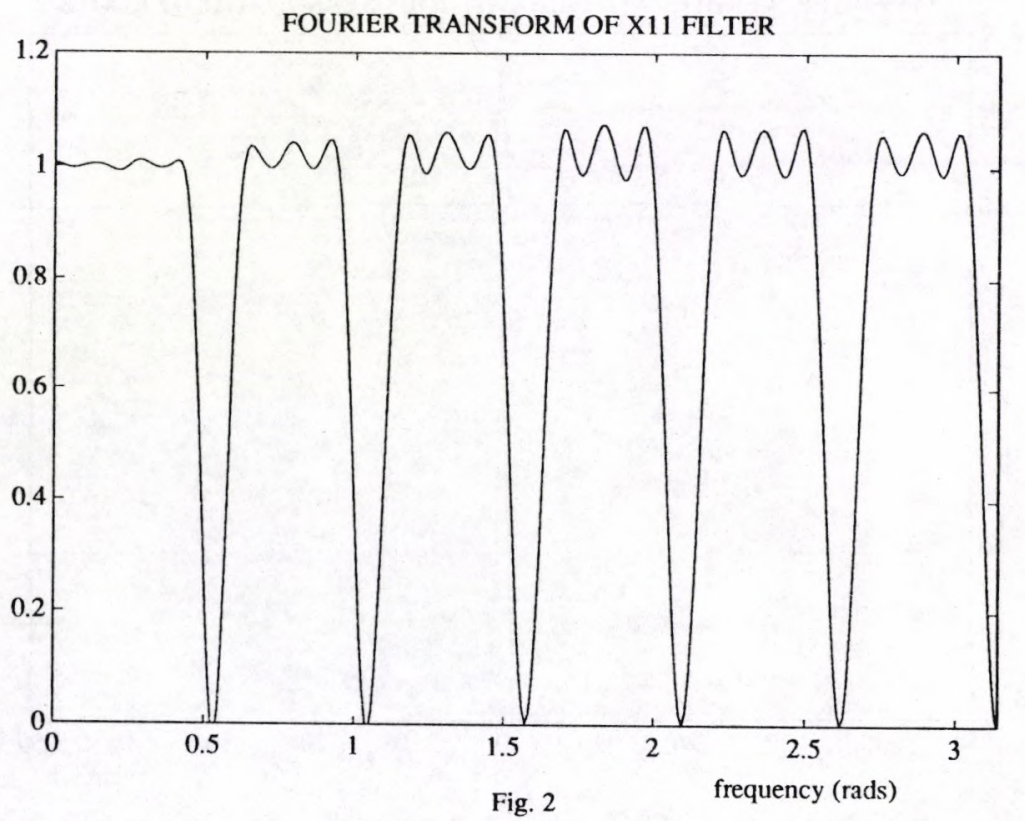




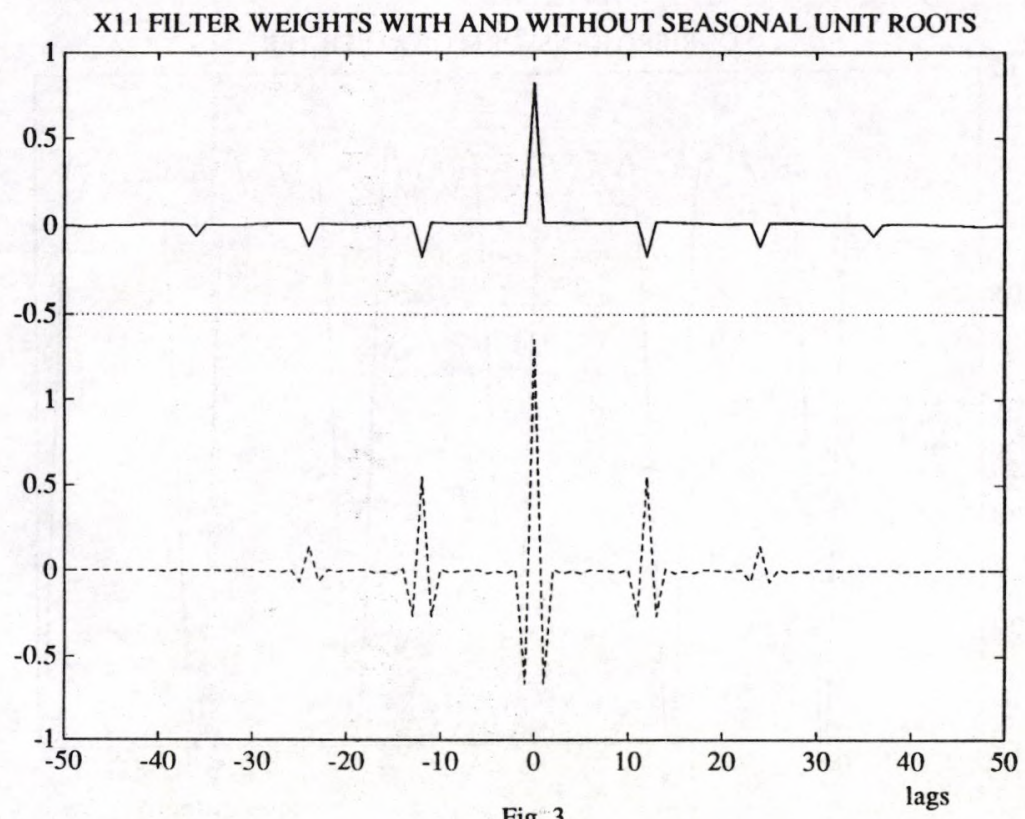

Fig. 3

Weights for full filter

Weights for filter without seasonal unit roots 
a) Theoretical Component

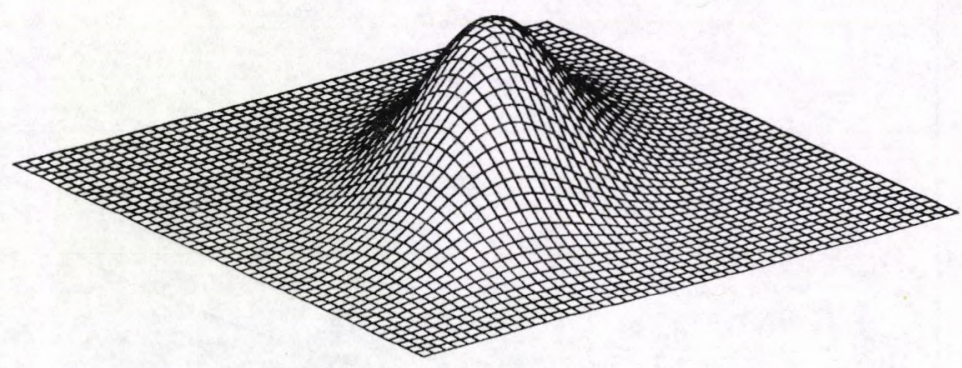

b) Final Estimator

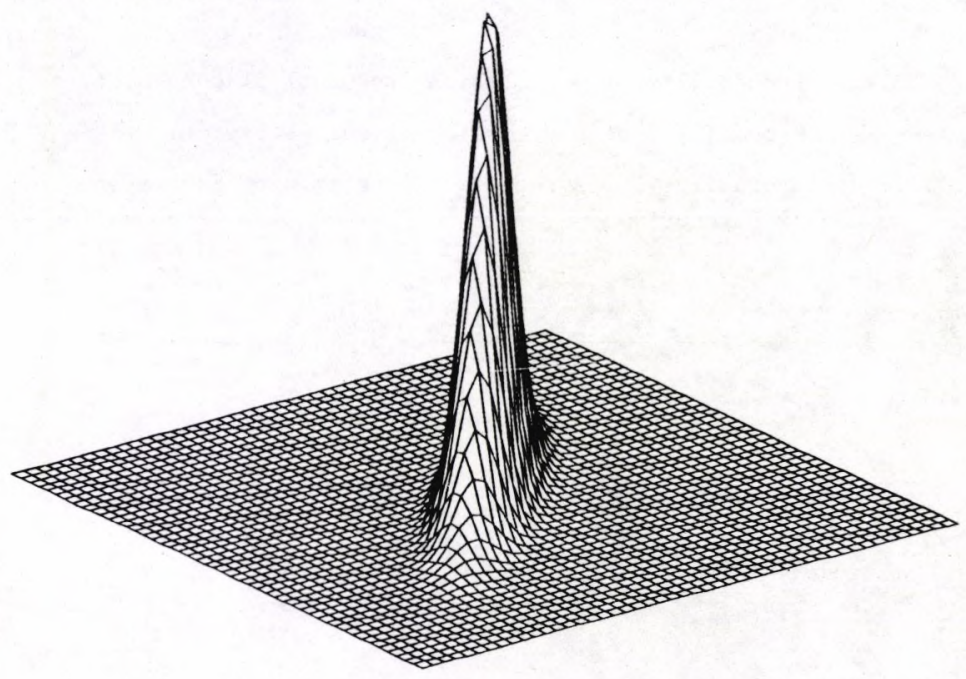

Fig. 4 


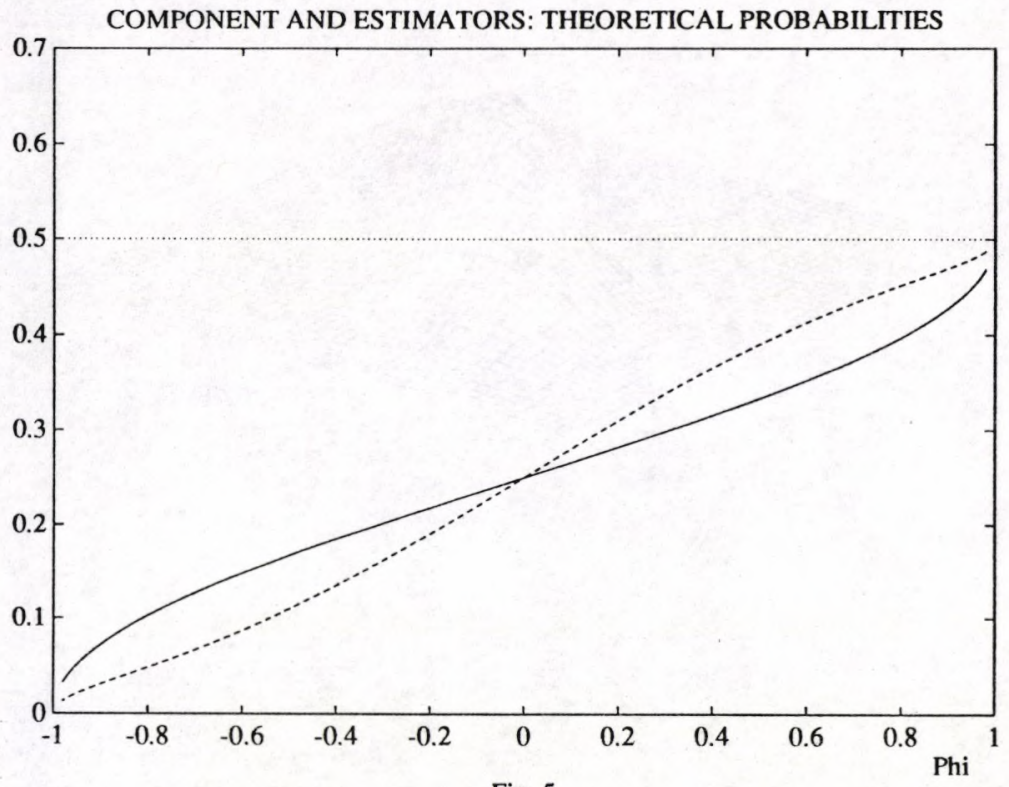

Fig. 5

Probability of a recession (theoretical component)

Probability of a recession (final estimator)

Probability of a recession (preliminary estimator or forecast) 


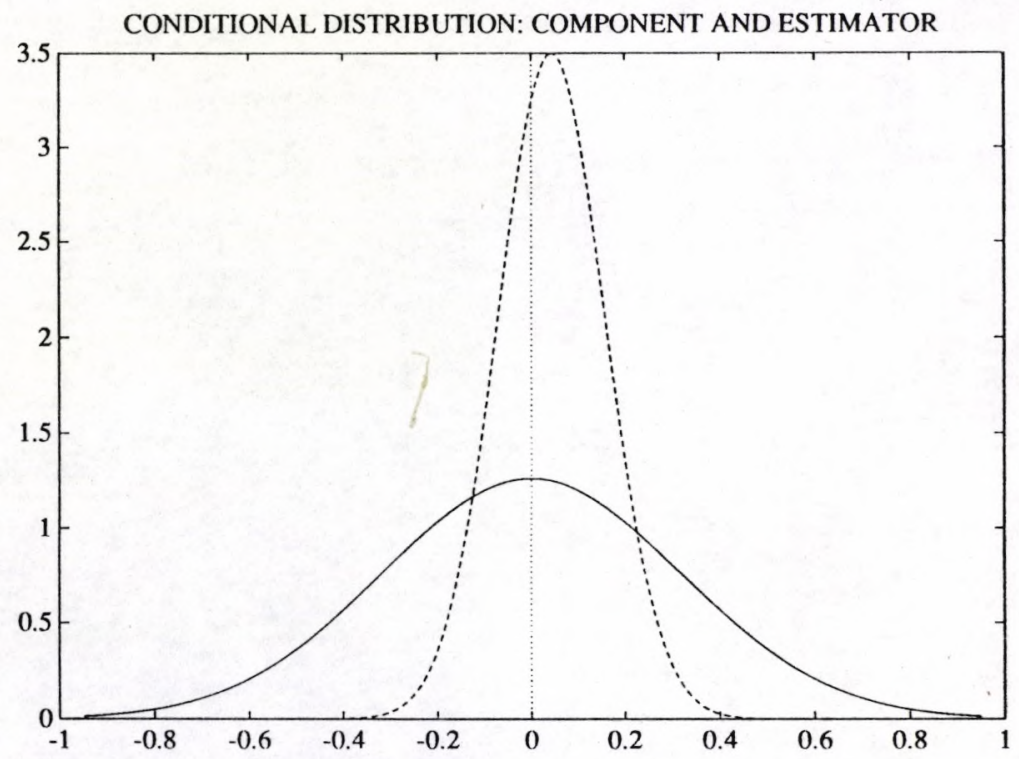

Fig. 6

_ Theoretical Component

---- Final Estimator 


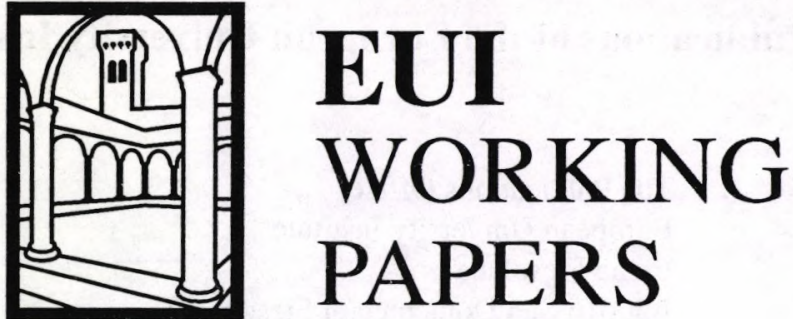

EUI Working Papers are published and distributed by the European University Institute, Florence

Copies can be obtained free of charge

- depending on the availability of stocks - from:

The Publications Officer

European University Institute

Badia Fiesolana

I-50016 San Domenico di Fiesole (FI)

Italy 


\title{
Publications of the European University Institute
}

To

\author{
The Publications Officer \\ European University Institute \\ Badia Fiesolana \\ I-50016 San Domenico di Fiesole (FI) \\ Italy
}

From

Name .....................

Address.

$\square$ Please send me a complete list of EUI Working Papers

$\square$ Please send me a complete list of EUI book publications

$\square$ Please send me the EUI brochure Academic Year 1993/94

$\square$ Please send me the EUI Research Report

Please send me the following EUI Working Paper(s):

No, Author

Title:

No, Author

Title:

No, Author

Title:

No, Author

Title:

Date

Signature 


\section{Working Papers of the Department of Economics Published since 1990}

ECO No. 90/1

Tamer BASAR and Mark SALMON

Credibility and the Value of Information

Transmission in a Model of Monetary

Policy and Inflation

ECO No. 90/2

Horst UNGERER

The EMS - The First Ten Years

Policies - Developments - Evolution

ECO No. 90/3

Peter J. HAMMOND

Interpersonal Comparisons of Utility:

Why and how they are and should be made

ECO No. 90/4

Peter J. HAMMOND

A Revelation Principle for (Boundedly)

Bayesian Rationalizable Strategies

ECO No. 90/5

Peter J. HAMMOND

Independence of Irrelevant Interpersonal

Comparisons

ECO No. 90/6

Hal R. VARIAN

A Solution to the Problem of

Externalities and Public Goods when

Agents are Well-Informed

ECO No. 90/7

Hal R. VARIAN

Sequential Provision of Public Goods

ECO No. 90/8

T. BRIANZA, L. PHLIPS and J.F. RICHARD

Futures Markets, Speculation and

Monopoly Pricing

ECO No. 90/9

Anthony B. ATKINSON/ John

MICKLEWRIGHT

Unemployment Compensation and

Labour Market Transition: A Critical

Review

ECO No. 90/10

Peter J. HAMMOND

The Role of Information in Economics
ECO No. 90/11

Nicos M. CHRISTODOULAKIS

Debt Dynamics in a Small Open

Economy

ECO No. 90/12

Stephen C. SMITH

On the Economic Rationale for

Codetermination Law

ECO No. 90/13

Elettra AGLIARDI

Learning by Doing and Market Structures

ECO No. 90/14

Peter J. HAMMOND

Intertemporal Objectives

ECO No. 90/15

Andrew EVANS/Stephen MARTIN

Socially Acceptable Distortion of

Competition: EC Policy on State Aid

ECO No. 90/16

Stephen MARTIN

Fringe Size and Cartel Stability

ECO No. 90/17

John MICKLEWRIGHT

Why Do Less Than a Quarter of the

Unemployed in Britain Receive

Unemployment Insurance?

ECO No. 90/18

Mrudula A. PATEL

Optimal Life Cycle Saving With

Borrowing Constraints:

A Graphical Solution

ECO No. 90/19

Peter J. HAMMOND

Money Metric Measures of Individual and Social Welfare Allowing for

Environmental Externalities

ECO No. 90/20

Louis PHLIPS/

Ronald M. HARSTAD

Oligopolistic Manipulation of Spot

Markets and the Timing of Futures

Market Speculation 
ECO No. 90/21

Christian DUSTMANN

Earnings Adjustment of Temporary

Migrants

ECO No. 90/22

John MICKLEWRIGHT

The Reform of Unemployment

Compensation:

Choices for East and West

ECO No. 90/23

Joerg MAYER

U. S. Dollar and Deutschmark as

Reserve Assets

ECO No. 90/24

Sheila MARNIE

Labour Market Reform in the USSR:

Fact or Fiction?

ECO No. 90/25

Peter JENSEN/

Niels WESTERGÅRD-NIELSEN

Temporary Layoffs and the Duration of

Unemployment: An Empirical Analysis

ECO No. 90/26

Stephan L. KALB

Market-Led Approaches to European

Monetary Union in the Light of a Legal

Restrictions Theory of Money

ECO No. 90/27

Robert J. WALDMANN

Implausible Results or Implausible Data?

Anomalies in the Construction of Value

Added Data and Implications for Esti-

mates of Price-Cost Markups

ECO No. 90/28

Stephen MARTIN

Periodic Model Changes in Oligopoly

ECO No. 90/29

Nicos CHRISTODOULAKIS/

Martin WEALE

Imperfect Competition in an Open

Economy
米洸

ECO No. 91/30

Steve ALPERN/Dennis J. SNOWER

Unemployment Through 'Learning From

Experience'

ECO No. 91/31

David M. PRESCOTT/Thanasis

STENGOS

Testing for Forecastible Nonlinear

Dependence in Weekly Gold Rates of

Return

ECO No. 91/32

Peter J. HAMMOND

Harsanyi's Utilitarian Theorem:

A Simpler Proof and Some Ethical

Connotations

ECO No. 91/33

Anthony B. ATKINSON/

John MICKLEWRIGHT

Economic Transformation in Eastern

Europe and the Distribution of Income*

ECO No. 91/34

Svend ALBAEK

On Nash and Stackelberg Equilibria

when Costs are Private Information

ECO No. 91/35

Stephen MARTIN

Private and Social Incentives

to Form R \& D Joint Ventures

ECO No. 91/36

Louis PHLIPS

Manipulation of Crude Oil Futures

ECO No. 91/37

Xavier CALSAMIGLIA/Alan KIRMAN

A Unique Informationally Efficient and

Decentralized Mechanism With Fair

Outcomes

ECO No. 91/38

George S. ALOGOSKOUFIS/

Thanasis STENGOS

Testing for Nonlinear Dynamics in

Historical Unemployment Series

ECO No. 91/39

Peter J. HAMMOND

The Moral Status of Profits and Other

Rewards:

A Perspective From Modern Welfare

Economics 
ECO No. 91/40

Vincent BROUSSEAU/Alan KIRMAN

The Dynamics of Learning in Mis-

Specified Models

ECO No. 91/41

Robert James WALDMANN

Assessing the Relative Sizes of Industryand Nation Specific Shocks to Output

ECO No. 91/42

Thorsten HENS/Alan KIRMAN/Louis PHLIPS

Exchange Rates and Oligopoly

ECO No. 91/43

Peter J. HAMMOND

Consequentialist Decision Theory and

Utilitarian Ethics

ECO No. 91/44

Stephen MARTIN

Endogenous Firm Efficiency in a Cournot

Principal-Agent Model

ECO No. 91/45

Svend ALBAEK

Upstream or Downstream Information Sharing?

\section{ECO No. 91/46}

Thomas H. McCURDY/

Thanasis STENGOS

A Comparison of Risk-Premium

Forecasts Implied by Parametric Versus

Nonparametric Conditional Mean

Estimators

ECO No. 91/47

Christian DUSTMANN

Temporary Migration and the Investment into Human Capital

ECO No. 91/48

Jean-Daniel GUIGOU

Should Bankruptcy Proceedings be

Initiated by a Mixed

Creditor/Shareholder?

ECO No. 91/49

Nick VRIEND

Market-Making and Decentralized Trade

ECO No. 91/50

Jeffrey L. COLES/Peter J. HAMMOND

Walrasian Equilibrium without Survival:

Existence, Efficiency, and Remedial

Policy
ECO No. 91/51

Frank CRITCHLEY/Paul MARRIOTT/

Mark SALMON

Preferred Point Geometry and Statistical Manifolds

ECO No. 91/52

Costanza TORRICELLI

The Influence of Futures on Spot Price

Volatility in a Model for a Storable

Commodity

ECO No. 91/53

Frank CRITCHLEY/Paul MARRIOTT/

Mark SALMON

Preferred Point Geometry and the Local Differential Geometry of the Kullback-

Leibler Divergence

ECO No. $91 / 54$

Peter MØLLGAARD/

Louis PHLIPS

Oil Futures and Strategic

Stocks at Sea

ECO No. 91/55

Christian DUSTMANN/

John MICKLEWRIGHT

Benefits, Incentives and Uncertainty

ECO No. 91/56

John MICKLEWRIGHT/

Gianna GIANNELLI

Why do Women Married to Unemployed Men have Low Participation Rates?

ECO No. 91/57

John MICKLEWRIGHT

Income Support for the Unemployed in Hungary

ECO No. 91/58

Fabio CANOVA

Detrending and Business Cycle Facts

ECO No. 91/59

Fabio CANOVAV

Jane MARRINAN

Reconciling the Term Structure of

Interest Rates with the Consumption

Based ICAP Model

ECO No. 91/60

John FINGLETON

Inventory Holdings by a Monopolist

Middleman 
米洸深

ECO No. 92/61

Sara CONNOLLY/John

MICKLEWRIGHT/Stephen NICKELL

The Occupational Success of Young Men

Who Left School at Sixteen

ECO No. 92/62

Pier Luigi SACCO

Noise Traders Permanence in Stock

Markets: A Tâtonnement Approach.

I: Informational Dynamics for the Two-

Dimensional Case

ECO No. 92/63

Robert J. WALDMANN

Asymmetric Oligopolies

ECO No. 92/64

Robert J. WALDMANN /Stephen

C. SMITH

A Partial Solution to the Financial Risk and Perverse Response Problems of

Labour-Managed Firms: Industry-

Average Performance Bonds

ECO No. 92/65

Agustín MARAVALL/Víctor GÓMEZ

Signal Extraction in ARIMA Time Series Program SEATS

ECO No. 92/66

Luigi BRIGHI

A Note on the Demand Theory of the Weak Axioms

ECO No. 92/67

Nikolaos GEORGANTZIS

The Effect of Mergers on Potential

Competition under Economies or

Diseconomies of Joint Production

ECO No. 92/68

Robert J. WALDMANN/

J. Bradford DE LONG

Interpreting Procyclical Productivity:

Evidence from a Cross-Nation Cross-

Industry Panel

ECO No. 92/69

Christian DUSTMANN/John

MICKLEWRIGHT

Means-Tested Unemployment Benefit

and Family Labour Supply: A Dynamic

Analysis
ECO No. 92/70

Fabio CANOVA/Bruce E. HANSEN

Are Seasonal Patterns Constant Over

Time? A Test for Seasonal Stability

ECO No. 92/71

Alessandra PELLONI

Long-Run Consequences of Finite

Exchange Rate Bubbles

ECO No. 92/72

Jane MARRINAN

The Effects of Government Spending on

Saving and Investment in an Open

Economy

\section{ECO No. 92/73}

Fabio CANOVA and Jane MARRINAN

Profits, Risk and Uncertainty in Foreign

Exchange Markets

ECO No. 92/74

Louis PHLIPS

Basing Point Pricing, Competition and

Market Integration

ECO No. 92/75

Stephen MARTIN

Economic Efficiency and Concentration:

Are Mergers a Fitting Response?

ECO No. 92/76

Luisa ZANCHI

The Inter-Industry Wage Structure:

Empirical Evidence for Germany and a

Comparison With the U.S. and Sweden

ECO NO. 92/77

Agustín MARAVALL

Stochastic Linear Trends: Models and

Estimators

ECO No. 92/78

Fabio CANOVA

Three Tests for the Existence of Cycles in Time Series

ECO No. 92/79

Peter J. HAMMOND/Jaime SEMPERE

Limits to the Potential Gains from Market Integration and Other Supply-Side Policies 
ECO No. 92/80

Víctor GÓMEZ and Agustín

MARAVALL

Estimation, Prediction and Interpolation for Nonstationary Series with the

Kalman Filter

ECO No. 92/81

Víctor GÓMEZ and Agustín

MARAVALL

Time Series Regression with ARIMA

Noise and Missing Observations

Program TRAM

ECO No. 92/82

J. Bradford DE LONG/ Marco BECHT

"Excess Volatility" and the German

Stock Market, 1876-1990

ECO No. $92 / 83$

Alan KIRMAN/Louis PHLIPS

Exchange Rate Pass-Through and Market

Structure

ECO No. 92/84

Christian DUSTMANN

Migration, Savings and Uncertainty

ECO No. 92/85

J. Bradford DE LONG

Productivity Growth and Machinery

Investment: A Long-Run Look, 18701980

ECO NO. 92/86

Robert B. BARSKY and J. Bradford DE LONG

Why Does the Stock Market Fluctuate?

ECO No. 92/87

Anthony B. ATKINSON/John

MICKLEWRIGHT

The Distribution of Income in Eastern

Europe

ECO No.92/88

Agustín MARAVALL/Alexandre

MATHIS

Encompassing Unvariate Models in Multivariate Time Series: A Case Study

ECO No. 92/89

Peter J. HAMMOND

Aspects of Rationalizable Behaviour
ECO 92/90

Alan P. KIRMAN/Robert

J. WALDMANN

I Quit

ECO No. 92/91

Tilman EHRBECK

Rejecting Rational Expectations in Panel

Data: Some New Evidence

ECO No. 92/92

Djordje Suvakovic OLGIN

Simulating Codetermination in a

Cooperative Economy

ECO No. 92/93

Djordje Suvakovic OLGIN

On Rational Wage Maximisers

ECO No. 92/94

Christian DUSTMANN

Do We Stay or Not? Return Intentions of

Temporary Migrants

ECO No. 92/95

Djordje Suvakovic OLGIN

A Case for a Well-Defined Negative

Marxian Exploitation

ECO No. $92 / 96$

Sarah J. JARVIS/John

MICKLEWRIGHT

The Targeting of Family Allowance in Hungary

ECO No. 92/97

Agustín MARAVALL/Daniel PEÑA

Missing Observations and Additive

Outliers in Time Series Models

ECO No. $92 / 98$

Marco BECHT

Theory and Estimation of Individual and

Social Welfare Measures: A Critical

Survey

ECO No. 92/99

Louis PHLIPS and Ireneo Miguel

MORAS

The AKZO Decision: A Case of

Predatory Pricing?

ECO No. 92/100

Stephen MARTIN

Oligopoly Limit Pricing With Firm-

Specific Cost Uncertainty 
ECO No. 92/101

Fabio CANOVA/Eric GHYSELS

Changes in Seasonal Patterns: Are They Cyclical?

ECO No. 92/102

Fabio CANOVA

Price Smoothing Policies: A Welfare

Analysis

棌深

ECO No. 93/1

Carlo GRILLENZONI

Forecasting Unstable and Non-Stationary

Time Series

ECO No. 93/2

Carlo GRILLENZONI

Multilinear Models for Nonlinear Time

Series

ECO No. 93/3

Ronald M. HARSTAD/Louis PHLIPS

Futures Market Contracting When You

Don't Know Who the Optimists Are

ECO No. 93/4

Alan KIRMAN/Louis PHLIPS

Empirical Studies of Product Markets

ECO No. 93/5

Grayham E. MIZON

Empirical Analysis of Time Series:

Illustrations with Simulated Data

ECO No. 93/6

Tilman EHRBECK

Optimally Combining Individual

Forecasts From Panel Data

ECO NO. 93/7

Víctor GÓMEZ/Agustín MARAVALL

Initializing the Kalman Filter with

Incompletely Specified Initial Conditions

ECO No. 93/8

Frederic PALOMINO

Informed Speculation: Small Markets

Against Large Markets

ECO NO. 93/9

Stephen MARTIN

Beyond Prices Versus Quantities
ECO No. 93/10

José María LABEAGA/Angel LóPEZ

A Flexible Demand System and VAT

Simulations from Spanish Microdata

ECO No. 93/11

Maozu LU/Grayham E. MIZON

The Encompassing Principle and

Specification Tests

ECO No. 93/12

Louis PHLIPS/Peter MØLLGAARD

Oil Stocks as a Squeeze Preventing

Mechanism: Is Self-Regulation Possible?

ECO No. 93/13

Pieter HASEKAMP

Disinflation Policy and Credibility: The

Role of Conventions

ECO No. 93/14

Louis PHLIPS

Price Leadership and Conscious

Parallelism: A Survey

ECO No. 93/15

Agustín MARAVALL

Short-Term Analysis of Macroeconomic

Time Series

ECO No. 93/16

Philip Hans FRANSES/Niels

HALDRUP

The Effects of Additive Outliers on Tests for Unit Roots and Cointegration

ECO No. 93/17

Fabio CANOVA/Jane MARRINAN

Predicting Excess Returns in Financial Markets

ECO No. 93/18

Iñigo HERGUERA

Exchange Rate Fluctuations, Market

Structure and the Pass-through

Relationship

ECO No. 93/19

Agustín MARAVALL

Use and Misuse of Unobserved

Components in Economic Forecasting 


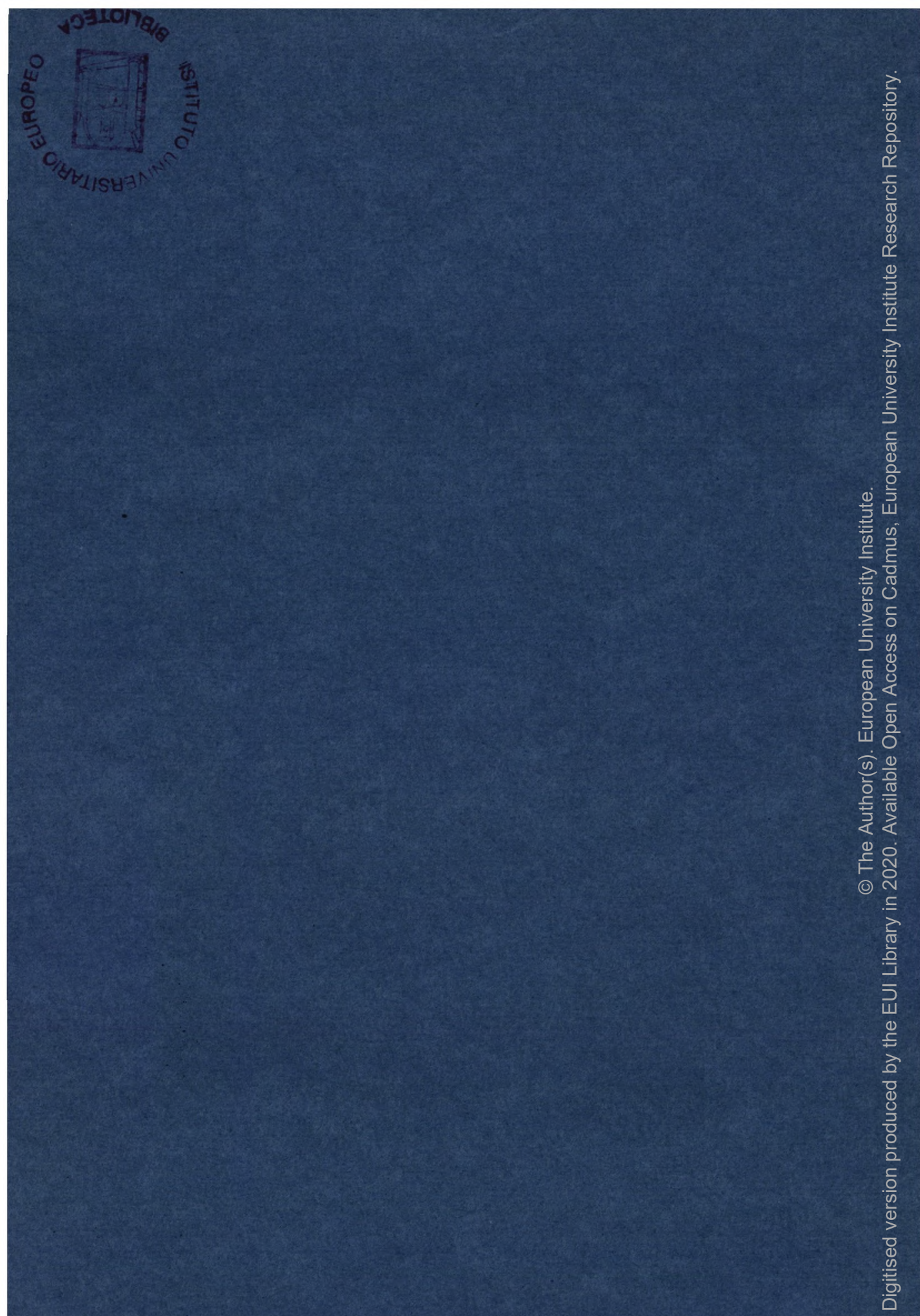

